\title{
SAÚDE DOCENTE: UM ESTUDO DE CASO NAS ESCOLAS MUNICIPAIS DE ENSINO FUNDAMENTAL DO MUNICÍPIO DE MATINHOS - PARANÁ - BRASIL
}

\author{
Josi Kelly Leite dos Santos ${ }^{1}$ \\ Universidade Federal do Paraná. Curitiba, Brasil \\ Clóvis Wanzinack \\ Universidade Federal do Paraná. Curitiba, Brasil
}

\begin{abstract}
Resumo. O trabalho realizado em condições inadequadas pode ser extremamente prejudicial ao trabalhador, gerar riscos à saúde e levar a sua inatividade. O objetivo desta pesquisa é discutir as condições de trabalho e saúde dos docentes da rede municipal de Matinhos, município situado no Litoral do Paraná - Brasil, focalizando a análise na violência enfrentada em sala de aula, nos problemas de saúde, no afastamento das atividades profissionais e nas dificuldades enfrentadas. Para realização do estudo, optou-se pelas pesquisas bibliográfica e exploratória, envolvendo 50 professores da rede municipal de ensino. A pesquisa constatou um índice de adoecimento de $62 \%$ dos sujeitos da pesquisa e violência sofrida por $40 \%$, além de $30 \%$ de afastamento por problemas de saúde e $34 \%$ de insatisfação com a profissão. Esses resultados alertam para a necessidade de se estabelecer políticas públicas direcionadas para a atenção à saúde e melhores condições de trabalho para os docentes.
\end{abstract}

Palavras-chave: Docentes, Condições de trabalho, Saúde do trabalhador.

\section{TEACHING HEALTH: A CASE STUDY IN THE MUNICIPAL SCHOOLS OF FUNDAMENTAL TEACHING OF THE MUNICIPALITY OF MATINHOS - PARANÁ - BRAZIL}

\begin{abstract}
Work, when held in inadequate conditions, can be extremely damaging for worker's health, leading sometimes to inactivity. The aim of this study is to discuss working and health conditions of those teachers working at the city of Matinhos, situated on the coast of Paraná. We focus on violence in classroom, health problems that leads to absenteeism and working difficulties. As research methods we have conducted a bibliographic review and exploratory research with 50 participants.

The data shows a high rate of illness among the teachers with about $62 \%$ of the respondents suffering from health problems, a high rate of violence suffered by the $40 \%, 30 \%$ absenteeism due to health problems and a large number of dissatisfaction within the profession (34\%). These results show the need of establishing public policies to improve health care and working conditions of these teachers.
\end{abstract}

Keywords: Teachers, working conditions, health of the worker.

1 Contato: cloviswa@gmail.com 


\section{SALUD DOCENTE: UN ESTUDIO DE CASO EN LAS ESCUELAS MUNICIPALES DE ENSEÑNANA FUNDAMENTAL DE LA CIUDAD DE MATINHOS - PARANÁ - BRAZIL}

Resumen. El trabajo realizado en condiciones inadecuadas puede ser extremamente perjudicial para el trabajador, generar riesgos para su salud y llevarle a su inactividad. El objetivo de este estudio es analizar las condiciones de trabajo y salud de los docentes de la red del ayuntamiento de Matinhos, una ciudad ubicada en el litoral de la provincia de Paraná - Brasil, centrándose en la violencia generada en clase, en los problemas de salud, el absentismo y en las dificultades que encuentran en la vida profesional. Para la realización del estudio se ha seguido una investigación bibliográfica y exploratoria, involucrando 50 profesores de la red de enseñanza del ayuntamiento. La investigación constató un índice de enfermedad de $62 \%$ de los sujetos investigados y violencia sufrida por el $40 \%$, además de un $30 \%$ de absentismo por problemas de salud y un 34\% de insatisfacción con la profesión. Los resultados indican la necesidad de establecer políticas públicas encaminadas a la atención a la salud y a conseguir mejores condiciones de trabajo para los docentes.

Palabras clave: Docentes, condiciones de trabajo, salud del trabajador.

\section{Introdução}

O trabalho é o resultado da força física e mental, gera bens, envolve serviços e atende a necessidades básicas, colaborando para o desenvolvimento da sociedade. É uma atividade de suma importância na vida do ser humano, pois, além de ser sua fonte de renda, favorece a sensação de ser útil, produtivo e valorizado.

No ambiente de trabalho, desenvolvem-se vários sentimentos, várias reações e até mesmo problemas relacionados à saúde, as chamadas doenças ocupacionais que comprometem o trabalhador (Laurell e Noriega, 1989). Ao ser realizado em condições inadequadas, pode, portanto, ser prejudicial, lesar a saúde do trabalhador, provocar alguns tipos de doenças e levar até mesmo a sua inatividade (Maciel, Fernandes e Medeiros, 2006).

No âmbito educacional, a estruturação do capitalismo e a globalização ocasionaram modificações na área, com mudanças na valorização social da profissão, que geraram repercussões sobre a saúde física e mental do docente. A maior dessas repercussões é identificada pela expressão 'mal-estar docente', condição cujas causas são classificadas em: a) fatores primários: aspectos que agem diretamente sobre a ação do professor em sala de aula, gerando tensões e sentimentos negativos; b) fatores secundários: condições de trabalho que agem indiretamente sobre a imagem do professor (Esteve, 1999). 
Como problemas relacionados às condições de trabalho, destacam-se os baixos salários, o ruído e a superlotação das salas, o cansaço físico pela longa jornada, a dupla jornada das professoras (doméstica e profissional), a falta de recursos materiais, os problemas familiares dos alunos, a multiplicidade de tarefas, o uso elevado da voz, a falta de valorização do trabalho realizado, o estado psicológico dos alunos, a burocratização das atividades educativas, as dificuldades nas relações com as famílias dos alunos, a falta de diálogo com a administração, a violência na escola (brigas entre alunos, roubos, ameaças por parte dos alunos, depredação do espaço), a necessidade de levar parte do trabalho para seu domicílio (preparação de aulas, correção de provas), a dificuldade de participação em cursos de aperfeiçoamento, a perda de autonomia, os movimentos repetitivos, as más condições de infraestrutura, a má higiene e limpeza escolar, a insegurança quanto à demissão, os salários em atraso, a falta de concursos públicos e o consequente crescimento da contratação temporária, o sentimento de culpa por não dar conta satisfatoriamente de todas as atividades, a padronização do currículo e dos métodos de ensino, a falta de acompanhamento técnico, o assédio moral, o fato de estar na escola dando aula e também ter que atender pais e alunos, inclusive em horários de pausa e alimentação (Souza e Leite, 2011).

O mal-estar docente é um fenômeno social e promove uma crise de identidade em que o professor passa a se questionar sobre a sua escolha profissional e o próprio sentido da profissão. Assim, os profissionais passam a manifestar sentimentos como angústia, ansiedade e desmotivação, além de exaustão emocional, sendo que a tarefa de ensinar, em geral, conforme alertam Reis, Araújo, Carvalho e Barbalho (2006), passa a ser uma atividade estressante, com reflexos na saúde física e mental e no desempenho profissional.

A violência é um problema vivenciado no mundo e na escola não é diferente. Ela consiste em ações humanas de indivíduos, grupos, classes, nações que ocasionam a morte de outros seres humanos ou afetam a integridade física, moral, mental ou espiritual (Minayo e Souza, 1999). Um ato de violência é toda ou qualquer agressão física, moral ou institucional direcionada contra a integridade de um ou de vários indivíduos (Abramovay, 2005).

Também não podemos subestimar o bullying corporativo. No ambiente de trabalho, ele é caracterizado por maus tratos contra uma pessoa de forma repetitiva e prejudicial à saúde, podendo consistir em abuso verbal, comportamento ameaçador, humilhações e até mesmo sabotagens que impeçam a realização do trabalho. De acordo com estudo realizado pelo Instituto WBI e pelo Zogby International nos Estados Unidos, $37 \%$ dos trabalhadores americanos haviam sofrido bullying no trabalho, $13 \%$ disseram que o problema estava acontecendo, $24 \%$ disseram que não estavam sofrendo 
no momento, porém já haviam sofrido, $12 \%$ já testemunharam, mas não sofreram diretamente. Somando-se quem já sofreu com quem está sofrendo e quem já testemunhou, obtém-se um total de $49 \%$, ou seja, praticamente metade dos trabalhadores entrevistados sofrem com esse fenômeno, sendo que a maioria dos agressores são homens (60\%) e 54\% dos seus alvos são homens e $46 \%$ mulheres, enquanto as mulheres elegem $71 \%$ das outras mulheres como alvo. O bullying converte o local de trabalho em um lugar onde todos sofrem, sendo que sua prática pode iniciar por agressões pessoais que podem tomar maiores proporções e, ao serem ignoradas, incidem em uma organização em risco (Namie, 2013).

Estudos mostram que os afastamentos dos docentes de suas atividades podem estar relacionados diretamente com as condições de trabalho a que estão expostos. $\mathrm{O}$ número de estudos realizados nessa área no Brasil aumentou a partir da década de 1990, sugerindo um crescimento da precarização das condições de trabalho dos docentes que inclui a desvalorização do trabalho e da remuneração, a falta de recursos tanto materiais quanto humanos, a infraestrutura, a postura corporal, a exposição química, os múltiplos empregos que sobrecarregam a força de trabalho desses profissionais (Souza e outros, 2003).

O objetivo deste estudo é discutir as condições de trabalho e saúde de profissionais da educação, por meio da análise de estudos precedentes relacionados à saúde do trabalhador e da pesquisa que envolve uma amostragem aleatória de docentes da rede municipal de Matinhos, focalizando a discussão na violência em sala de aula, nos preconceitos, nos problemas de saúde e afastamentos decorrentes, considerando em destaque as reais dificuldades enfrentadas por esses docentes na profissão.

\section{Método}

O estudo contou com o apoio de referenciais teóricos sobre a temática e o uso da pesquisa exploratória, realizada no município de Matinhos, localizado no litoral do Paraná. Destaca-se que a rede municipal conta com oito escolas municipais e nove Centros Municipais de Educação Infantil (CMEI), um número que facilita a coleta de dados.

Para a coleta de dados, foi utilizado um questionário com questões fechadas e mistas, caracterizando o uso das abordagens qualitativa e quantitativa. Enquanto a abordagem quantitativa centra sua atenção na objetividade, pois considera que a realidade é compreendida com base na análise de dados brutos, recorrendo '... à linguagem matemática para descrever as causas de um fenômeno, as relações entre variáveis, etc." (Gerhardt e Silveira, 2009, p. 20), a abordagem qualitativa tem como 
foco dados não mensuráveis quantitativamente, mas que servem para exercer um amplo entendimento sobre a real situação do entrevistado em seus comentários.

O questionário foi aplicado via plataformas online, como e-mails e redes sociais, e diretamente nas escolas. Ao ser distribuído aleatoriamente no campo presencial e virtual na região da pesquisa, foi acompanhado por informações sobre os objetivos da pesquisa e pelo Termo de Consentimento Livre e Esclarecido (TCLE), confirmando a opção de cada sujeito participar da pesquisa. Participaram do estudo 50 professores da rede municipal de ensino, com idade entre 26 e 55 anos.

Após o recebimento dos questionários, os dados foram tabulados e confrontados com a literatura pesquisada, ampliando a análise das reais condições de saúde e trabalho dos professores participantes. A partir desse confronto, foram levantadas sugestões relacionadas a melhorias para que esses profissionais continuem suas carreiras de forma digna e satisfatória e que possam favorecer tanto os próprios docentes quanto os estudantes.

\section{Resultados e discussões}

Os docentes envolvidos nesta pesquisa são formados, em sua maior parte, pelo gênero feminino, conforme registrado na Tabela 1. Essa condição confirma mais uma vez a predominância da mulher na profissão da docência, um fenômeno internacional relatado desde 1800, associado à industrialização e à expansão da escolaridade (Hypolito, 1997).

No decorrer do século XX, a docência também foi assumida como uma atividade eminentemente feminina (Vianna, 2001). E, apesar de se ampliar a participação dos homens a cada etapa do ensino regular, dados recentes confirmam mais uma vez a predominância feminina quando destacam que a educação básica no Brasil conta com 1.882,961 docentes, dos quais 1.542,925 mulheres. No tocante ao Ensino Médio, há 267.174 professoras e 147.381 professores (Assis, 2009).

Tabela 1. Perfil dos professores participantes da pesquisa $(\mathrm{n}=50)$

\begin{tabular}{l|l|l}
\hline \multirow{2}{*}{ Gênero } & Feminino & $84 \%$ \\
& Masculino & $16 \%$ \\
\hline \multirow{5}{*}{ Cor/Raça/Etnia } & Amarela & $2 \%$ \\
& Indígena & $4 \%$ \\
& Preta & $6 \%$ \\
& Parda & $24 \%$ \\
& Branca & $58 \%$ \\
& Outros & $2 \%$ \\
& Não se identifica & $4 \%$ \\
\hline \multirow{2}{*}{ Estado Civil } & Solteiro & $12 \%$ \\
& Casado & $68 \%$ \\
\hline
\end{tabular}




\begin{tabular}{l|l|l}
\hline & Viúvo & $2 \%$ \\
& Outros & $2 \%$ \\
& & $94 \%$ \\
\multirow{3}{*}{ Orientação Sexual } & Heterossexual & $2 \%$ \\
& Homossexual & $4 \%$ \\
\hline \multirow{3}{*}{ Escolaridade } & Não se reconhece & $4 \%$ \\
& Ensino Superior Incompleto & $40 \%$ \\
& Ensino Superior Completo & $4 \%$ \\
& Aperfeiçoamento & $50 \%$ \\
& Especialização & $2 \%$ \\
\hline
\end{tabular}

Fonte: Os autores

Em relação à formação e à atuação, constatou-se que $63 \%$ dos homens possuem nível de escolaridade em alguma especialização, já as mulheres alcançaram 48\%; elas superam em aproximadamente 10 anos o tempo de trabalho como docente em relação aos homens; cerca de $50 \%$ dos homens exercem outra atividade além da docência, enquanto as mulheres alcançam o índice de $19 \%$.

No que diz respeito a enfermidades, $62 \%$ das mulheres e $37 \%$ dos homens relataram adoecimento em função da profissão. As principais queixas de adoecimento e dificuldades enfrentadas foram iguais para os dois gêneros: os problemas psíquicos, osteomusculares e vocais, a desvalorização da profissão, a indisciplina dos alunos e a falta de material.

Destaca-se também que os homens apresentam maior grau de insatisfação na profissão, mas não foram constatados casos de depressão nas queixas entre os homens, diferentemente das mulheres, o que reforça a indicação de Araújo e Carvalho (2009) de que as mulheres apresentam prevalência na maioria dos problemas de saúde já investigados.

Ainda de acordo com o estudo, cerca de $40 \%$ dos docentes têm seu tempo de serviço entre 11 e 20 anos. As maiores queixas de adoecimentos estão justamente nessa faixa, atingindo $30 \%$ dos sujeitos da pesquisa; em contrapartida com os primeiros 10 anos de profissão, quando as queixas chegam a $8 \%$. Quanto à violência, $40 \%$ das mulheres e $32 \%$ dos homens já se deparam com esse problema, confirmando mais uma condição adversa que permeia a profissão.

O trabalho do professor não se restringe somente a sua função em sala de aula, ele envolve outras atividades, além das ligadas à escola, têm as tarefas domésticas, problemas familiares, e principalmente a cobrança e as mudanças da sociedade (Esteve, 1999). Nesse sentido, os sujeitos pesquisados afirmam que, com o passar do tempo, há uma sobrecarga, ocasionando sintomas de estresse, cansaço mental, cansaço físico e entre outros.

Nesse ínterim, o que se percebe é que os professores têm sofrido tanto uma exigência de posturas pela sociedade, como problemas relativos aos recursos tanto materiais quanto humanos. Em decorrência, observam-se modificações no contexto 
social das últimas décadas que alteraram o perfil do professor e as exigências pessoais e do meio em relação à eficácia de sua atividade (Esteve, 1999).

Nos últimos vinte anos, a implantação de diferentes programas dentro das escolas públicas tem marcado uma nova regulamentação na área educacional, que traz consequências significativas, implicando na intensificação do trabalho, tanto pelo aumento das atividades quanto pelo aumento do número de alunos por sala (Almeida, Neves e Santos, 2013).

A própria pesquisa pode evidenciar a existência de um índice relativo de alunos por turma, sendo que $54 \%$ dos docentes têm suas salas de aula com a média de 25 alunos e $20 \%$ chegando a 30 alunos. Segundo entrevistados/as:

O grande número de alunos em sala de aula atrapalha o andamento da aula, assim inviabilizando término do planejamento feito para a determinada... (Entrevistada 20).

O número expressivo de alunos em sala de aula, nos prejudica devido ao elevado uso da voz necessário para que todos nos ouçam de forma adequada, devido à bagunça e falta de atenção dos alunos... (Entrevistada 14).

Azevedo e outros (2009) lembram que as queixas do adoecimento vocal podem estar relacionadas tanto ao não conhecimento de técnicas vocais adequadas para lecionar quanto às condições de trabalho desfavoráveis, como o forte ruído, o número alto de alunos em sala, as salas com padrão acústico ruim, o barulho que tende a ser competitivo, entre outros.

Outro resultado relevante da pesquisa delimitou que $42 \%$ dos docentes têm sua carga horária semanal máxima, $14 \%$ destes completam sua carga horária em diferentes escolas e $19 \%$ trabalham com mais de 5 turmas. Esses dados convergem com estudos desenvolvidos pelo país que apontam que a carga horária de trabalho ultrapassa o que é de direito, sendo que, na maioria das vezes, parte das atividades são realizadas em casa, além da ocupação de horários extras com a participação em cursos de formação e capacitação profissional, que também são realizados fora da carga horária de trabalho exigida (Neves e Silva, 2006). Os intervalos muitas vezes são inexistentes, o que obriga os docentes a continuar em suas salas de aula, acompanhando os alunos que retardam atividades ou, em outros casos, realizando funções que não lhes conferem (Santos, 2009, Brito e outros 2014).

$\mathrm{Na}$ maior parte dos casos, a carga de trabalho se amplia com o trabalho doméstico, configurando mais um fator que contribui para a sobrecarga do trabalho docente, o que incide em que parte já chega exausta em sala de aula no início da semana (Hypolito, 1997). A pesquisa revela ainda que $24 \%$ dos docentes exerce outra atividade, muitos devido à necessidade de complementação de renda, em função da desvalorização da profissão, conforme expressado na sequência por sujeitos da pesquisa. 
A valorização salarial é extremamente baixa, tenho dois filhos e sou sozinha, portanto necessito de uma renda razoável para nos manter. (Entrevistada 39).

Leciono o dia todo, e faço bicos no período da noite, no meu caso é exaustivo e estressante, mas necessário para minha estabilidade no momento. (Entrevistada 24).

As condições de trabalho geralmente precárias dos professores apontam a desvalorização do trabalho docente principalmente no Ensino Fundamental, frisando que os professores das escolas públicas brasileiras têm até tripla jornada de trabalho como estratégia para aumentar sua remuneração (Neves e Silva, 2006).

No quesito violência, a pesquisa demonstra que $40 \%$ dos professores já foram expostos a alguma forma, seja verbal, psicológica e/ou física. A análise da violência no ambiente escolar é fundamental na discussão sobre condições de trabalho e saúde dos docentes, pois ela se constitui em um ato de brutalidade humana, de abuso físico e psíquico contra o indivíduo (Chauí, 1999).

Ainda sobre os dados obtidos no estudo, cerca de $70 \%$ dos respondentes afirmaram que, de certa forma, essa exposição acarretou mudanças em suas funções em sala de aula, conforme pode ser observado nos seguintes relatos:

Senti muito medo, pensei em até desistir da profissão... (Entrevistada 37).

Fiquei muito assustada, com medo, magoada minha relação com meus alunos mudou muito, minha forma de lecionar mudou, e para mim é muito difícil fazer está afirmação... (Entrevistada 06).

Resultados de vários estudos ratificam que o desgaste produzido pela violência no ambiente escolar torna ainda mais difícil o trabalho docente (Rocha, 2012).

Gráfico 1. Deparar com situações de preconceito $(n=50)$

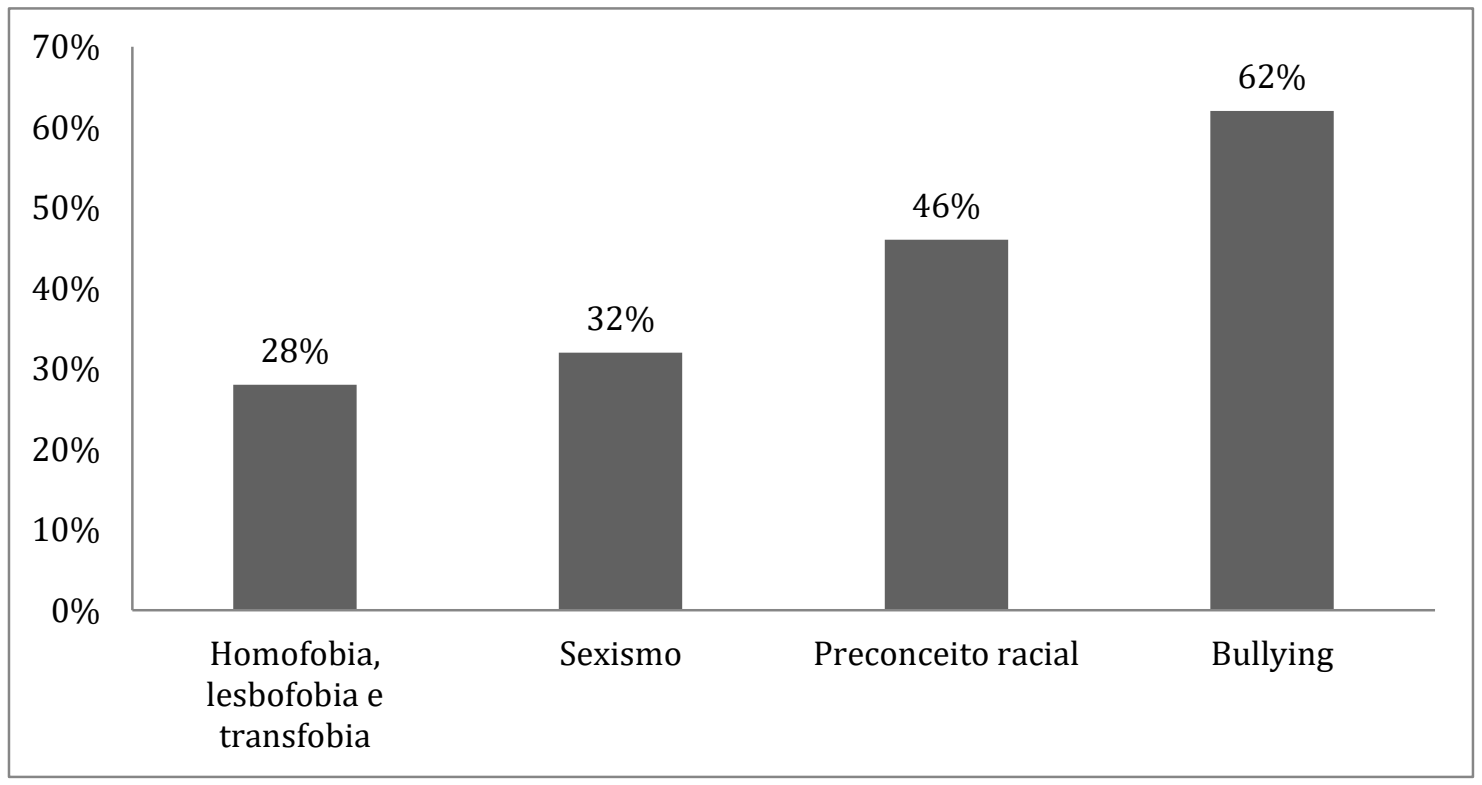

Fonte: Os autores 
A homofobia é aplicada não só aos homossexuais, mas a toda pessoa que tem (ou parece ter) alguma identidade que se atribui ao outro sexo (Welzer-Lang, 2000).

Não sou homossexual, também não haveria problema em ser, porém já sofri muito com esse preconceito devido ao tom de minha voz ser muito grossa, no início era mais complicado, hoje sou mais tranquila... (Entrevistada 31).

No âmbito da violência contra a mulher, o estudo revela uma incidência de $32 \%$. Vale destacar que o sexismo é a discriminação em relação às pessoas de outro sexo, reconhecendo a violência contra mulheres e todos aqueles que, em determinado modo, são reconhecidos como tendo uma posição feminilizada (Von Smigay, 2008).

Ele não me aceitou como parceira para viabilizar um projeto junto a ele na escola onde lecionamos, dando a entender que eu não seria capaz de realiza-lo... (Entrevistada 28).

Sinto-me muitas vezes excluída, deixada de lado por meus colegas de trabalho, por ter uma idade mais avançada que eles/as... (Entrevistada 11).

Outro preconceito muito enfrentado é o racial, que pode ser entendido como o resultado de crenças, normas, valores sociais, como fatores ideológicos influenciadores de separação de comportamento. É nesse sentido que se constata o preconceito não como consequência de características psicológicas individuais, mas como resultado de relações de poder entre grupos (Camino e Pereira, 2000), tal como uma antipatia baseada numa generalização falha e inflexível, que pode ser sentida e/ou expressa e que pode ser dirigida a um grupo ou a um indivíduo porque ele faz parte daquele grupo (Allport, 1954). A pesquisa demonstra que $46 \%$ dos docentes já se depararam com o preconceito racial, conforme reforçam os seguintes relatos:

Diversas vezes fui apontada como aquela professora meio índia... (Entrevistada, 50).

Várias vezes fui xingada por alunos/as devido minha cor de pele, xingamentos como: professora do cabelo ruim, nega chata... (Entrevistada 21).

Ainda não fui vítima desse preconceito, porém já vi vários colegas passando por situações embaraçosas, esperamos que um dia esse mal tenha um fim porque é muito difícil você desempenhar seu papel em meio de tanta violência... (Entrevistada 07).

O bullying foi o que alcançou a porcentagem mais alta com $62 \%$, ou seja, mais da metade dos/as docentes já se depararam com essa situação.

Cheguei pela manhã à escola onde leciono, e meu nome estava escrito na parede com o adjetivo de gorda... (Entrevistada 27).

Na realidade, o bullying corporativo pode ser denominado como uma violência psicológica, em que o/a agressor/a impede o bom desempenho do alvo em seu trabalho (Namie, 2013). 
O estudo revela uma alta incidência de professores que relataram adoecimento em função da profissão, 62\%, ou seja, mais da metade dos docentes, e cerca de $30 \%$ dos respondentes já tiveram que se afastar de suas atividades em função disso. Na Tabela 2, estão listadas as principais queixas de adoecimento. No questionário aplicado, os respondentes poderiam assinalar mais de uma alternativa.

Tabela 2. Queixas de adoecimento $(n=50)$

\begin{tabular}{l|l}
\hline Estresse & $71 \%$ \\
\hline Problemas digestivos & $35.5 \%$ \\
\hline Depressão & $32,3 \%$ \\
\hline Esquecimento & $25,8 \%$ \\
\hline Problemas relacionados à poeira e ao pó de giz & $25,8 \%$ \\
\hline Rouquidão & $19,7 \%$ \\
\hline Redução da visão & $16,1 \%$ \\
\hline Dores de cabeça & $16,1 \%$ \\
\hline Fraqueza/Indisposição & $12,9 \%$ \\
\hline Queda de cabelo & $12,9 \%$ \\
\hline Falta de ar & $12,9 \%$ \\
\hline LER/Dor & $12,3 \%$ \\
\hline Dores de garganta & $10 \%$ \\
\hline Dores nas pernas & $10 \%$ \\
\hline Dores nos braços & $10 \%$ \\
\hline Tontura & $9,7 \%$ \\
\hline Perda temporária da voz & $9 \%$ \\
\hline Outros & $6,5 \%$ \\
\hline
\end{tabular}

Em relação aos problemas relatados na Tabela 2, os transtornos psíquicos foram as maiores queixas entre os docentes, com o estresse alcançando $71 \%$ e a depressão $32 \%$, sendo o primeiro o responsável por $16 \%$ dos afastamentos dos docentes de suas atividades. Estudos indicam que os transtornos psíquicos lideram entre os diagnósticos que provocam os afastamentos dos professores do trabalho (Gasparini, Barreto e Assunção, 2005).

A satisfação no trabalho constitui fator essencial, pois trabalhar sem ansiedade e sem medo faz com que se encontre significado nas atividades laborais (Dejours, 2012). As boas condições de trabalho são indispensáveis para uma atividade menos desgastante, mais prazerosa, mais produtiva e, obviamente, mais saudável para os docentes.

A pesquisa apontou que $34 \%$ dos professores se sentem pouco satisfeitos ou insatisfeitos, mostrando um reflexo das condições de trabalho com que eles se deparam diariamente em sala de aula. Na Tabela 3, estão listadas as principais dificuldades encontradas na profissão atualmente, relatadas pelos/as respondentes no questionário aplicado. 
Tabela 3. Dificuldades encontradas na profissão $(n=50)$

\begin{tabular}{l|l}
\hline Indisciplinas dos alunos & $38 \%$ \\
\hline Desvalorização da profissão & $32 \%$ \\
\hline Falta de material & $30 \%$ \\
\hline Controle da turma & $26 \%$ \\
\hline Grande número de alunos & $26 \%$ \\
\hline Falta de apoio e comprometimento dos pais & $26 \%$ \\
\hline Falta de interesse dos alunos em aprender & $18 \%$ \\
\hline Alunos/as com atraso significativo de aprendizagem & $10 \%$ \\
\hline Estrutura física & $8 \%$ \\
\hline Outros & $6 \%$ \\
\hline
\end{tabular}

Fonte: Os autores

É muito difícil você desenvolver alguma atividade num ambiente inadequado, com a falta e/ou com pouco material... (Entrevistada 18).

A profissão está muito desvalorizada, com salário inadequado, a participação dos pais está cada vez mais escassa, e a indisciplina dos alunos cada vez maior... (Entrevistada 02).

Para um ambiente de trabalho adequado, é fundamental um ambiente acolhedor, uma estrutura física adequada e recursos materiais disponíveis para a realização das atividades, uma administração séria, competente e com diálogo, a participação ativa dos pais no ambiente escolar e, principalmente, maior valorização da profíssão. Além disso, a falta de reconhecimento é uma das queixas mais citadas pelos professores em diversos estudos (Neves e Silva, 2006). Pesquisas ainda apontam que, perante os constrangimentos, as exigências e as pressões no trabalho, os professores relatam a existência expressiva de um mal-estar (Esteve, 1999).

\section{Considerações finais}

O corpo docente desta pesquisa é formado, em sua maior parte, pelo gênero feminino, que chega a atingir $84 \%$ dos sujeitos implicados, dado que corresponde à maioria como em outros territórios brasileiros. Do quadro pesquisado, constatou-se um alto índice de adoecimento, com cerca de 62\%, um elevado índice de bullying, com $62 \%$, um elevado grau de violência, com $40 \%$, um índice de $30 \%$ de afastamento devido a problemas de saúde gerados pela profissão e um número expressivo de insatisfação que atinge $34 \%$ dos pesquisados.

Esses resultados reforçam outros indicadores de outras regiões e localidades brasileiras, confirmando a desvalorização da profissão que é relatada em vários estudos sobre a temática. Os adoecimentos identificados associaram-se ao tempo de trabalho como docente, à elevada carga horária semanal, aos múltiplos empregos, ao ambiente escolar em condições inadequadas, às questões psicológicas que a execução da profissão exige e até mesmo à cobrança do próprio professor em atender as mudanças e exigências da educação. 
Apesar de ser um estudo exploratório, cuja responsabilidade é expor um panorama sem adentrar profundamente nas especificidades, a pesquisa evidencia um número significativo de queixas de doenças em função da profissão, portanto a necessidade de melhorias na infraestrutura, de mais investimentos nas organizações escolares e em materiais necessitados, da inserção de programas para melhorar a disciplina dos alunos e estimular a participação dos pais no ambiente escolar.

Em decorrência dos resultados, observa-se a imprescindibilidade de se estabelecer políticas públicas direcionadas para a atenção e prevenção à saúde e melhores condições de trabalho desses docentes. Contudo, ainda assim é possível aos educadores transformarem a árdua tarefa em algo prazeroso, em função das relações afetivas que criam com seus alunos, o que possibilita e estimula a busca de melhores alternativas para realizar o trabalho que lhes conferem (Dejours, 2012).

\section{Referências}

Abramovay, M. (2005). Violencia en las escuelas: un gran desafío. Revista iberoamericana de educación, (38), 53-66.

Almeida, M. R. D., Neves, M. Y., e Santos, F. A. D. (2013). Implicações das políticas educacionais nas vivências subjetivas de professoras de escolas públicas. Cadernos de Psicologia Social do Trabalho, 16(2), 241-257.

Allport, G. W. (1954). The nature of prejudice. Reading: Addison-Wesley.

Araújo, T. M. D., e Carvalho, F. M. (2009). Condições de trabalho docente e saúde na Bahia: Estudos Epidemiológicos. Educação e Sociedade, 30(107), 427-449, maio/agosto. Recuperado em 20 agosto de 2016, de http://www.scielo.br/pdf/es/v30n107/07.pdf.

Assis, L. M. (2009). Estudo exploratório sobre o professor brasileiro com base nos resultados do Censo Escolar da Educação Básica 2007. Nacional de Estudos e Pesquisas Educacionais Anísio Teixeira. Brasília: Inep.

Azevedo, L. L. D., Vianello, L., Oliveira, H. G. P. D., Oliveira, I. D. A., Oliveira, B. F. V. D., e Silva, C. M. D. (2009). Queixas vocais e grau de disfonia em professoras do ensino fundamental. Revista Sociedade Brasileira de Fonoaudiologia, 14(2), 192-196.

Brito, J. e outros (2014). Saúde, gênero e reconhecimento no trabalho das professoras: convergências e diferenças no Brasil e na França. Physis: Revista de Saúde Coletiva, 24(2). 589-605. Recuperado em 22 de julho de 2016, de http://dx.doi.org/10.1590/S0103-73312014000200014.

Camino, L., e Pereira, C. (2000). O papel da psicologia na construção dos direitos humanos: Análise das teorias e práticas psicológicas na discriminação ao homossexualismo. Revista Perfil, 13(13), 49-69. 
Carvalho, F. M., e Barbalho, L. (2006). Docência e exaustão emocional. Educ. Soc, 27(94), 229-253.

Chauí, M. (1999). Uma ideologia perversa. Folha de S. Paulo, 14(03).

Dejours, C. (2012). Outra forma de civilidade: a cooperação. Em C. Dejours. Trabalho vivo: trabalho e emancipação. Paralelo, 15, 75-112.

Esteve, J. M. (1999). O mal-estar docente: a sala de aula e a saúde dos professores. São Paulo: EDUSC.

Gasparini, S. M., Barreto, S. M., e Assunção, A. A. (2005). O professor, as condições de trabalho e os efeitos sobre sua saúde. Educação e Pesquisa, 31(2), 189-199.

Gerhardt, T. E., e Silveira, D. T. (2009). Métodos de pesquisa Porto Alegre: Editora da UFRGS.

Hypolito, Á. M. (1997). Trabalho docente, classe social e relações de gênero. São Paulo: Papirus.

Laurell, A. C., e Noriega, M. (1989). Processo de produção e saúde: trabalho e desgaste operário. São Paulo: Hucitec.

Maciel, Á. C. C., Fernandes, M. B., e Medeiros, L. S. (2006). Prevalência e fatores associados à sintomatologia dolorosa entre profissionais da indústria têxtil. Revista Brasileira de Epidemiologia, 9(1), 94-102.

Minayo, M. C. D. S., e Souza, E. R. D. (1999). É possível prevenir a violência? Reflexões a partir do campo da saúde pública. Ciência \& Saúde Coletiva, 4(1), $7-23$.

Namie, G. (2013). Bullying no trabalho. Tradução de Eduardo Rieche. Rio de Janeiro: Best Business.

Neves, M. Y. R., e Silva, E. S. (2006). A dor e a delícia de ser (estar) professora: trabalho docente e saúde mental. Estudos e Pesquisas em Psicologia,6(1), 6375 .

Reis, E. J. F. B., Araújo, T. M., Carvalho, F. M., Barbalho, L., e Silva, M. O. (2006). Docência e exaustão emocional. Educação e Sociedade, 27(94), 229-253.

Rocha, T. B. (2012). Cyberbullying: ódio, violência virtual e profissão docente. Brasília: Liber Livro.

Santos, G. B. D. (2009). Os professores e seus mecanismos de fuga e enfrentamento. Trab. educ. saúde, 7(2), 285-304.

Souza, A. N. e Leite, M. P. (2011). Condições de trabalho e suas repercussões na saúde dos professores da educação básica no Brasil. Educação e Sociedade, 32(117), 1105-1121. 
Souza, K. R., Santos, M. B. M., Pina, J. Á., Maria, A. B. V., Carmo, M. A. T., e Jensen, M. (2003). A trajetória do Sindicato Estadual dos Profissionais da Educação do Rio de Janeiro (Sepe-RJ) na luta pela saúde no trabalho. Ciências Saúde Coletiva, 8(4), 1057-68.

Vianna, C. P. (2001). O sexo e o gênero da docência. Cadernos Pagu, 17(18), 81-103.

Von Smigay, K. E. (2008). Sexismo, homofobia e outras expressões correlatas de violência: desafios para a psicologia política. Psicologia em Revista, 8(11), 3246.

Welzer-Lang, D. (2000). A construção do masculino: dominação das mulheres e homofobia. Red Revista Estudos Feministas.

Data de recebimento: 01/12/2016

Data de revisão: $15 / 12 / 2016$

Data do aceite: $11 / 01 / 2017$ 